(c) 2020 Universidad Nacional Autónoma de México, Facultad de Estudios Superiores Zaragoza.

Este es un artículo Open Access bajo la licencia CC BY-NC-ND (http://creativecommons.org/licenses/by-nc-nd/4.0/).

TIP Revista Especializada en Ciencias Químico-Biológicas, 23: 1-7, 2020.

https://doi.org/10.22201/fesz.23958723e.2020.0.269

\title{
Cultivo in vitro de Lactarius volemus en la búsqueda de lectinas fúngicas
}

\author{
Yesenia Aragón-López*, Alma Dolores Pérez-Santiago \\ y Marco Antonio Sánchez-Medina \\ Tecnológico Nacional de México/Instituto Tecnológico de Oaxaca. Unidad \\ de Bioquímica e Inmunología ITO-UNAM. Avenida Ing. Víctor Bravo Ahuja \\ \#125 esq. Calzada Tecnológico, Oaxaca de Juárez, 68030, Oaxaca, México. \\ E-mail: *yesaragon12@gmail.com
}

\begin{abstract}
RESUMEN
Las lectinas de los hongos, son substancias de potente actividad biológica, que se obtienen de diferentes partes de la seta, tallos y micelios. Oaxaca posee una gran diversidad fúngica, con 13 especies de hongos silvestres comestibles provenientes de la Sierra de Oaxaca, y de los que solo seis presentan actividad hemaglutinante, como Lactarius volemus, que puede poseer al menos una lectina y para su aislamiento se prepararon cajas de Petri con agar sobre el que se colocó un fragmento de lámina del hongo, además de un medio líquido consistente en extracto de malta. Los bioensayos en medio líquido se llevaron a cabo en un período de 10 días en condiciones estáticas y en agitación a 50 rpm en la oscuridad y a una temperatura de $25^{\circ} \mathrm{C}$, monitoreando la biomasa miceliar, la cantidad de cel $/ \mathrm{mL}$ presentes y variación del $\mathrm{pH}$ que fue de entre 4.6 y 3.4 además de cuantificar las proteínas.
\end{abstract}

Palabras clave: lectina, hongo, biomasa, proteína, $\mathrm{pH}$.

\section{In vitro culture of Lactarius volemus in the search for fungal lectins}

\begin{abstract}
The lectins of the fungi are substances of powerful biological activity, which are found in different parts of the mushroom, stems and mycelia. Oaxaca has great fungal diversity, with 13 species of edible wild mushrooms from the Sierra de Oaxaca, and of which only six have hemagglutinating activity, such as Lactarius volemus, which may have at least one lectin and boxes of Petri dish with agar on which a fragment of the fungus lamina was placed, in addition to a liquid medium consisting of malt extract. Bioassays in liquid medium are controlled over a period of 10 days under static conditions and with agitation at $50 \mathrm{rpm}$ in the dark and at a temperature of $25^{\circ} \mathrm{C}$, monitoring the mycelial biomass, the amount of cel $/ \mathrm{mL}$ present and the variation in $\mathrm{pH}$ that it was between 4.6 and 3.4 in addition to quantifying the proteins. Keywords: lectin, fungus, biomass, protein, $\mathrm{pH}$.
\end{abstract}




\section{INTRODUCCIÓN}

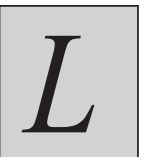

os habitantes del estado de Oaxaca poseen una vasta experiencia sobre el uso y manejo del medio ambiente, entre cuyas prácticas figura la recolección de diversos hongos silvestres que forman parte del patrón alimenticio de los oaxaqueños (García-Mendoza, Ordóñez \& Briones-Salas, 2004).

Los hongos comestibles silvestres, han sido utilizados desde épocas prehispánicas en México por su alto contenido nutritivo y sus propiedades medicinales, características por las que forman parte importante del reservorio de hongos, a nivel mundial (Boa, 2004).

En los últimos años, las lectinas fúngicas han suscitado gran interés, debido al descubrimiento de su potente actividad biológica y por lo mismo se les ha aislado a partir de cuerpos fructíferos, recientemente se han publicado algunos trabajos sobre la obtención del micelio y en algunos casos del extracto extracelular de los hongos (Tsivileva, Nikitina \& Loshchinina, 2008).

La primera lectina de hongos "phallin" fue descubierta en Amanita phalloides (Kobert, 1893) y en Lactarius que es uno de los géneros de hongos basidiomicetos más estudiados. Las lectinas, han sido ubicadas en el cuerpo fructífero de Lactarius rufus (Panchak1 \&Antonyuk, 1999), Lactarius lignyotus (Khan \& Khan, 2011), Lactarius deliciousus (Guillot, Giollant, Damez \& Dusser, 1991a), Lactarius deterrimus (Giollant et al., 1993a) y Lacatarius flavidulus (Yingying, Hexiang \& Tzi, 2011).

Entre los hongos del estado de Oaxaca hasta aquí citados sobresale $L$. volemus, porque además de formar parte del patrón alimenticio, tiene un gran uso potencial tanto medicinal (antitumoral), como biotecnológico en la producción de inoculantes para especies forestales y algunos árboles hospederos (Pinus teocote, P. dogulasiana, P. patula, P. pringlei, Quercus crassifolia, Q. laurina, Q. rugosa, Q. consatti y Q. urbanii) (Zamora-Martínez, González-Hernández, Islas-Gutiérrez, Cortés-Barrera \& López-Valdez, 2014).

Lactarius volemus es descrito como carnoso y generalmente robusto con píleo comúnmente llamado sombrero de color naranja pálido a parduzco, seco o algo pubescente; exuda látex abundante al roce o al corte y tiene un característico y fuerte olor que se suele describir como aguaturma (Asociación Micológica de Durango, http://www.errotari.com/Micologia/ especie.php?1754), su limitante es que se trata de un hongo silvestre que se da sólo una vez al año después de la temporada de lluvias, lo que restringe su accesibilidad.

De las 13 especies de hongos silvestres comestibles de la Sierra Norte de Oaxaca estudiadas, se reportó que este hongo presentó de 0.649 a $0.67 \mathrm{mg} / \mathrm{mL}$ de proteína total, afinidad por eritrocitos humanos tipo A, B y O, así como actividad hemaglutinante inhibida con N-acetil-D-galactosamina al 0.05 M y N-acetil-D-glucosamina al 0.0125 M, y que de acuerdo con su actividad hemaglutinante $L$. volemus puede poseer al menos una lectina (Sandoval, 2016).

El objetivo de esta investigación fue la identificación de la actividad hemaglutinante de los metabolitos de origen fúngico contenidos en el micelio cultivado sobre agar y sumergido en medio líquido.

El cultivo in vitro de L. volemus en medio líquido se obtuvo al inocular discos de agar con micelio para obtener una mayor cantidad de lectina del medio que la que puede extraerse directamente de los carpóforos; este inóculo favoreció el aislamiento de la lectina del medio de cultivo, su purificación y las condiciones para su producción controlando la temperatura, cantidad de biomasa inicial y $\mathrm{pH}$.

\section{MATERIALES Y MÉTODOS}

\section{Recolección y conservación de los cuerpos fructíferos}

Los cuerpos fructíferos u hongos se adquirieron en mercados locales de la ciudad de Oaxaca de Juárez, Oaxaca, provenientes de la Sierra Norte del estado durante los meses de agosto-octubre. Se guardaron en bolsas de cartón cubiertas de papel celulosa y todo esto en bolsas de polipapel y a $-20{ }^{\circ} \mathrm{C}$ en un congelador horizontal (Frigidaire, GLFC1526FW).

\section{Cultivo in vitro en medio sólido}

La muestra se tomó del cuerpo fructífero conservado en congelación. Al tejido seleccionado (lámina) se le realizaron cortes en secciones de aproximadamente $1 \mathrm{~cm}^{2}$ con un bisturí, lavando una parte con hipoclorito de sodio $(\mathrm{NaClO})$ al $5 \%$ y lo restante con peróxido de hidrógeno $\left(\mathrm{H}_{2} \mathrm{O}_{2}\right)$ al $3 \%$ durante 30 a 120 segundos, se enjuagaron con agua estéril y se colocaron, para su crecimiento, en la superficie de un medio sólido, el agar, con extracto de malta, medio líquido (CONDA), por un periodo de 6 días.

\section{Cultivo in vitro en medio líquido}

Para obtener la biomasa miceliar en un medio líquido, se realizaron diferentes bioensayos, seleccionando tres medios de cultivo para su crecimiento por seis días: caldo de suero de naranja, caldo de extracto de malta y caldo de papa dextrosa (MCD LAB) posterior al período de tiempo señalado se tomaron $100 \mathrm{~mL}$ de cada medio y un disco de agar con el micelio desarrollado en cada uno para someterlos a las mismas condiciones de temperatura y agitación $\left(25 \pm 2^{\circ} \mathrm{C}\right.$ a $\left.50 \mathrm{rpm}\right)$. Los siguientes bioensayos se realizaron con $50 \mathrm{~mL}$ del medio de cultivo caldo extracto de malta, inoculado en 6 discos ( 5 $\mathrm{mm}$ diámetro) con agar y micelio durante 10 días $\left(25 \pm 2^{\circ} \mathrm{C}\right.$ a $50 \mathrm{rpm}$ y sin agitación). 
Método espectrofotométrico (Escala de McFarland) para la cuantificación de biomasa

Mediante un recuento indirecto, es decir, la absorbancia es directamente proporcional a las cel $/ \mathrm{mL}$ presentes, se tomó lectura de la absorbancia a una longitud de onda de $425 \mathrm{~nm}$ (Spectronic 20 D). Se obtuvo una curva estándar para relacionar los valores obtenidos de absorbancia con el número de células (con una curva estándar de patrones con respecto a la escala de McFarland); las soluciones patrones corresponden a la preparación estándar donde la turbiedad de cada tubo (bien agitado, para suspender el sedimento), es proporcional al número de células de la suspensión.

\section{Determinación del pH}

Del medio en incubación se tomó lectura del pH (Pometer, $\mathrm{pH}$ 3C), para evaluar el cambio durante los días de crecimiento y determinar si la lectina se presenta como respuesta a la acidificación del medio.

\section{Ensayo de actividad hemaglutinante (AH)}

La prueba se llevó a cabo en una placa de micro titulación con fondo "U", se colocaron $50 \mu \mathrm{L}$ PBS ( $\mathrm{pH} 7.5$ ) en cada pozo de la placa, posteriormente se añadieron $50 \mu \mathrm{L}$ de la muestra efectuando diluciones dobles seriadas con un volumen final de $50 \mu \mathrm{L}$. Se adicionó a cada pozo $25 \mu \mathrm{L}$ de eritrocitos humanos (3\%). Como control, en los primeros pozos se colocó PBS y solución al 3\% de eritrocitos humanos del grupo $\mathrm{O} \mathrm{Rh}+$. Las lecturas se realizaron después de una hora a temperatura ambiente. Los resultados se registran como positivo (pozos con hemaglutinación) y negativo (no presenta hemaglutinación). La mayoría de las lectinas aglutinan eritrocitos de todos los grupos sanguíneos, las que son específicas aglutinan eritrocitos humanos preferentemente de un determinado grupo sanguíneo.

\section{Inhibición por carbohidratos}

Las pruebas de inhibición de la actividad hemaglutinante se realizaron en placas de micro titulación de 96 pozos, depositando
$50 \mu \mathrm{L}$ de PBS ( $\mathrm{pH} 7.5$ ) en todos los pozos de la placa, después se agregaron en ellos $50 \mu \mathrm{L}$ del carbohidrato a analizar, en una concentración de $0.4 \mathrm{M}$, se mezcló el azúcar con el PBS y se tomaron $50 \mu \mathrm{L}$ para realizar diluciones dobles seriadas a partir del segundo pozo. Posteriormente se agregan $50 \mu \mathrm{L}$ del extracto del hongo en cada pozo de la placa, en la misma concentración conocida (4 UHA). Finalmente se adicionan 25 $\mu \mathrm{L}$ de eritrocitos al $3 \%$ en cada pozo de la placa. La placa se deja reposar a temperatura ambiente por 1 hora. A partir de los pozos inhibidos se determina la concentración mínima de carbohidrato requerida para inhibir 4 UHA de lectina.

\section{Cuantificación de proteínas por el método de Bradford}

La concentración de proteínas se determinó de acuerdo con el método de Bradford (1976) usando una curva estándar BSA como curva estándar de calibración. Por cada mililitro de Bradford concentrado se agregan $4 \mathrm{~mL}$ de agua destilada, filtrando y agitando vigorosamente para obtener una solución patrón de la que se extraen $5 \mathrm{~mL}$ y se vierten con $100 \mu \mathrm{L}$ de la muestra en un tubo de ensayo, tomando lectura a $595 \mathrm{~nm}$ (Spectronic 20D).

\section{RESUltados}

\section{Morfología del hongo $L$. volemus}

El píleo o sombrero tiene un diámetro promedio que oscila entre los $7 \mathrm{~cm}$, la superficie es muy seca, presenta un color naranja rojizo (Figura 1 a), las láminas son apretadas entre sí, de color crema con un ligero matiz amarillento (Figura 2 b), el pie es macizo de color similar al sombrero, blanquecino próximo a las láminas (Figura $3 \mathrm{c}$ ).

\section{Morfología de las colonias de $L$. volemus}

La morfología micelial que presentan las cepas aisladas de un fragmento del cuerpo fructífero en el medio sólido, es circular, plana de superficie lisa, aspecto húmedo, consistencia suave, color crema-anaranjado (Figura 2), el interés por la morfología de las colonias es para tener la certeza de que se trabaja con L. volemus.

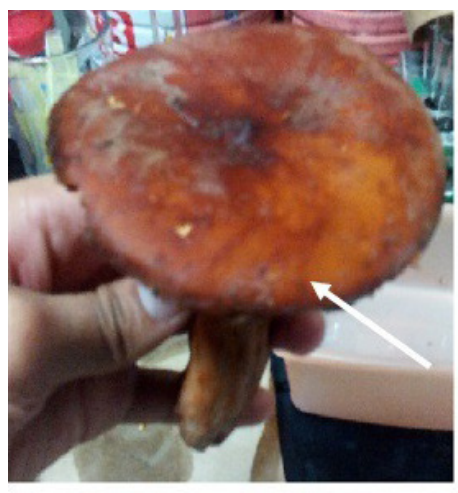

a

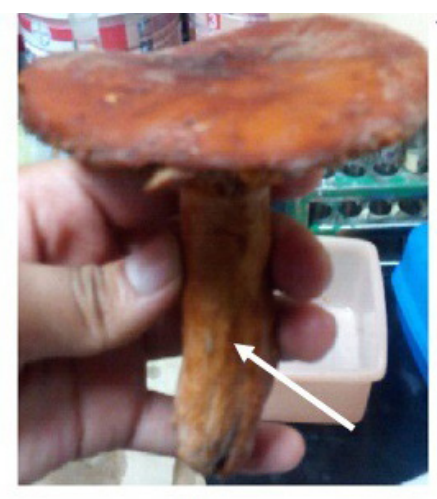

b

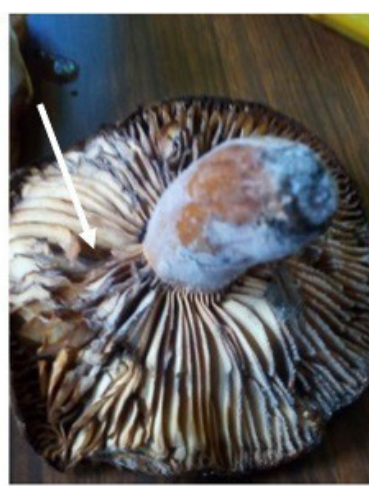

C

Figura 1. Estructura macroscópica de Lactarius volemus: a. Pileo b. Estipe (pie), c. Lámina 


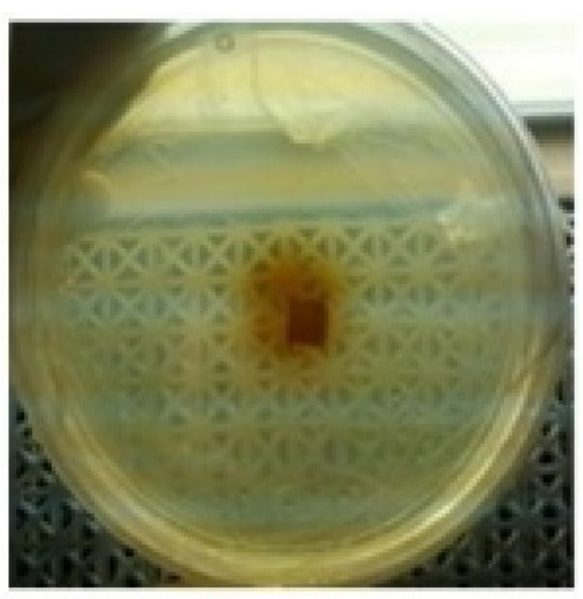

a

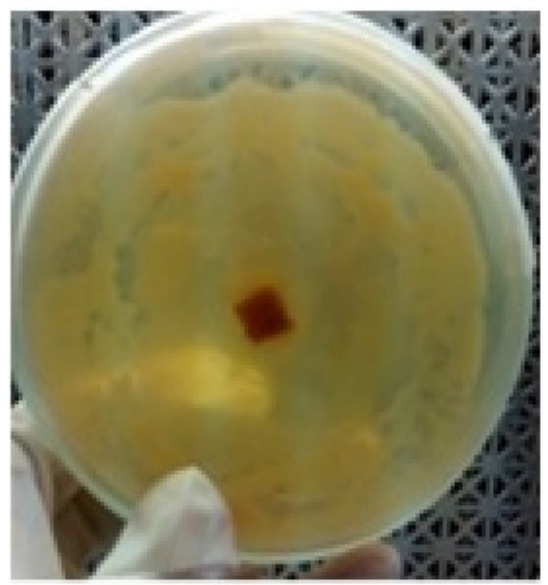

$\mathrm{b}$

Figura 2.Crecimiento micelial de Lactarius volemus. a) Crecimiento de 1 día, b) Crecimiento de 6 días.

\section{Producción de biomasa}

Los resultados que se presentan a continuación son de un medio de cultivo líquido inoculado en discos de agar-micelio, obtenidos a partir de la lectura de absorbancia en cada medio de cultivo (Tabla I) y que corresponden a cel/mL (de acuerdo a la escala de Macfarland) en un periodo de 10 días de crecimiento. Estos resultados se representan gráficamente mediante la cinética de crecimiento (Gráfica 1) donde se muestra que la mayor producción de biomasa se logra con el cultivo en agitación utilizando el caldo extracto de malta, que es muy diferente cuando se utiliza el medio caldo papa dextrosa también en condiciones de agitación donde se obtienen los más bajos crecimientos de biomasa.

En la Tabla II, se muestran las cel $/ \mathrm{mL}$ del medio caldo extracto de malta ( $50 \mathrm{~mL}$ del medio y 6 discos de agar-micelio), sin diferencia significativa en los días de crecimiento ver (Gráfica 2). A los 10 días en condiciones de agitación se obtuvo una

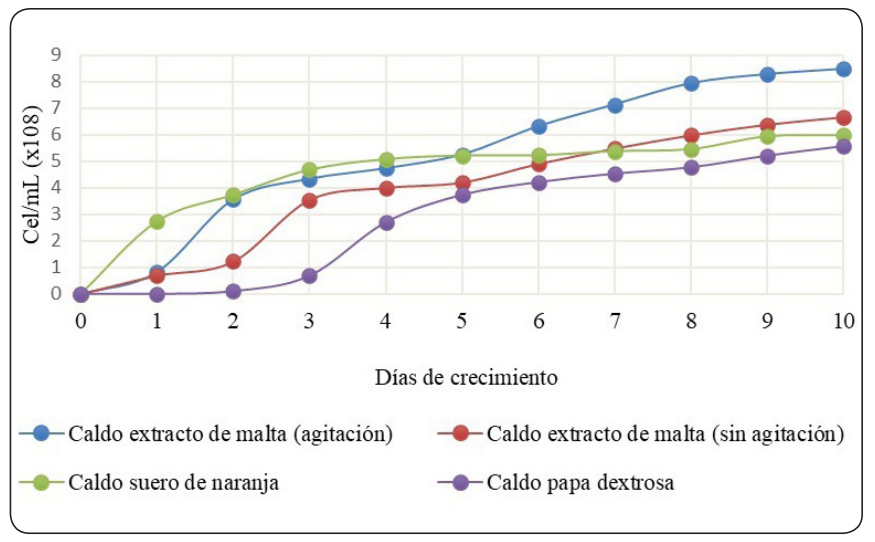

Gráfica 1. Cinética de crecimiento (inoculación con discos de agarmicelio) en diferentes medios de cultivo.

Tabla I. Crecimiento celular en diferentes medios de cultivo.

\begin{tabular}{|c|c|c|c|c|}
\hline \multirow{2}{*}{ Días } & \multicolumn{2}{|c|}{ Caldo extracto de malta } & Caldo suero de naranja & Caldo papa dextrosa \\
\cline { 2 - 5 } & $\mathbf{5 0} \mathbf{~ r p m}$ & Sin Agitación & $\mathbf{5 0} \mathbf{~ r p m}$ & $\mathbf{5 0} \mathbf{~ r p m}$ \\
\hline 1 & $\mathbf{C e l} / \mathbf{m L}$ & $\mathbf{C e l} / \mathbf{m L}$ & $\mathbf{C e l} / \mathbf{m L}$ & $\mathbf{C e l} / \mathbf{m L}$ \\
\hline 2 & 0.83 & 0.69 & 2.74 & 0.1 \\
\hline 3 & 3.56 & 1.22 & 3.74 & 0.68 \\
\hline 4 & 4.34 & 3.54 & 4.68 & 2.7 \\
\hline 5 & 4.74 & 4 & 5.08 & 3.74 \\
\hline 6 & 5.26 & 4.2 & 5.22 & 4.22 \\
\hline 7 & 6.32 & 4.9 & 5.23 & 4.54 \\
\hline 8 & 7.14 & 5.48 & 5.38 & 5.78 \\
\hline 9 & 7.94 & 5.98 & 5.46 & 5.58 \\
\hline 10 & 8.28 & 6.38 & 5.94 & 6.08 \\
\hline$* \operatorname{cel} / \mathrm{mL}\left(\mathrm{x} 10^{8}\right)$ & 8.48 & 6.66 & 5.98 & \\
\hline
\end{tabular}


Tabla II. Crecimiento en caldo extracto de malta.

\begin{tabular}{|c|c|c|}
\hline & Agitación 50 rpm & Sin Agitación \\
\hline Días & Cel/ $\mathbf{m L}$ & Cel/mL \\
\hline 1 & 4.6 & 4.75 \\
\hline 2 & 9.21 & 5.2 \\
\hline 3 & 9.24 & 9.42 \\
\hline 4 & 9.18 & 9.45 \\
\hline 5 & 9.17 & 9.24 \\
\hline 6 & 9.15 & 9.24 \\
\hline 7 & 9.14 & 9.25 \\
\hline 8 & 9.14 & 9.2 \\
\hline 9 & 8.28 & 6.46 \\
\hline 10 & 7.82 & 6.39 \\
\hline$*$ cel $/ \mathrm{mL}\left(\mathrm{x} 10^{8}\right)$ & \\
\hline
\end{tabular}

cantidad de biomasa de $7.82 \times 10^{8} \mathrm{cel} / \mathrm{mL}$ y en condiciones estáticas $6.39 \times 10^{8} \mathrm{cel} / \mathrm{mL}$.

\section{Actividad hemaglutinante}

En la Gráfica 3 se muestra la actividad de la lectina obtenida en los diferentes medios de cultivo, o sea que no se presenta en los pozos una diferencia significativa de actividad con y $\sin$ agitación, ya que el número de pozos positivos obtenidos son similares ( 2 y 3 pozos positivos), pero sí existe una diferencia con respecto a los días de crecimiento.

La presencia de lectina fue al tercer día (Gráfica 4), una vez que el hongo cultivado en el medio líquido pasó de su fase de crecimiento exponencial. En la Figura 3 se muestra el principio de una actividad hemaglutinante a los 9 días de crecimiento, donde el control negativo es la suspensión de eritrocitos y PBS sin la muestra, la (biomasa miceliar).

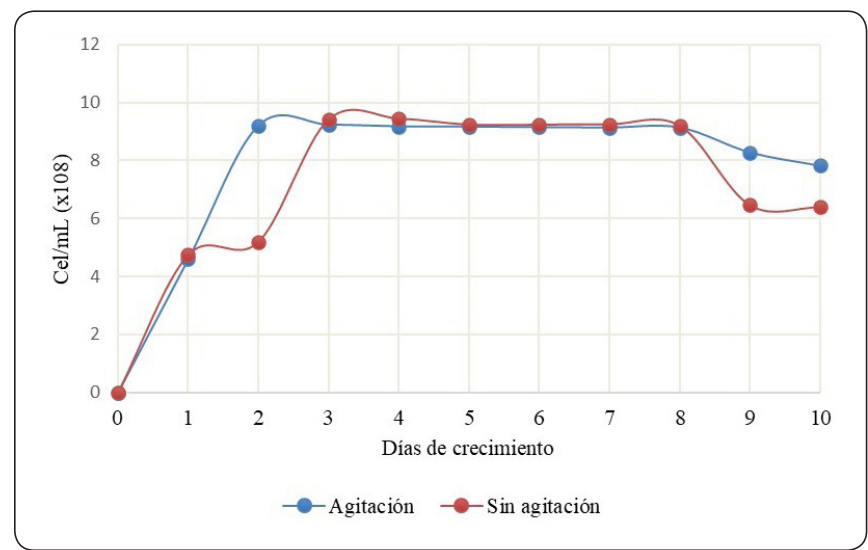

Gráfica 2. Cinética de crecimiento de $L$. volemus en caldo extracto de malta.

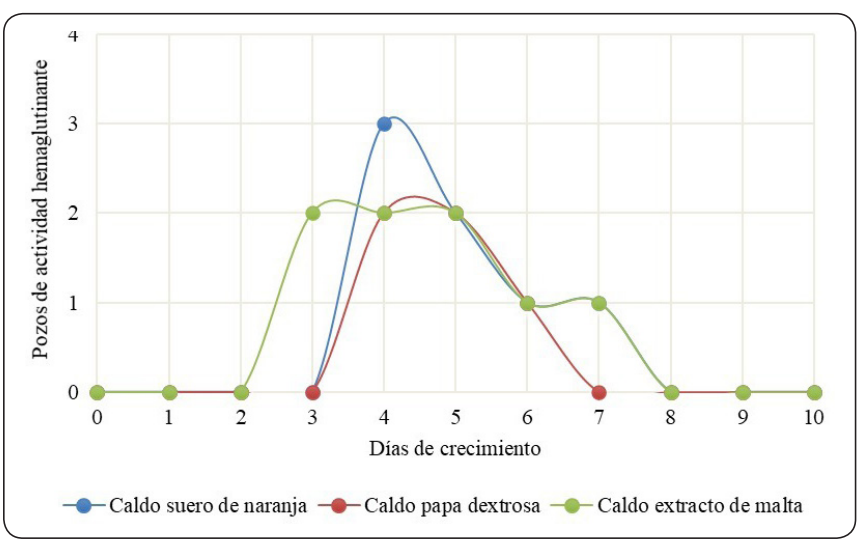

Gráfica 3. Cinética de actividad de la lectina de $L$. volemus en diferentes medios de cultivo.

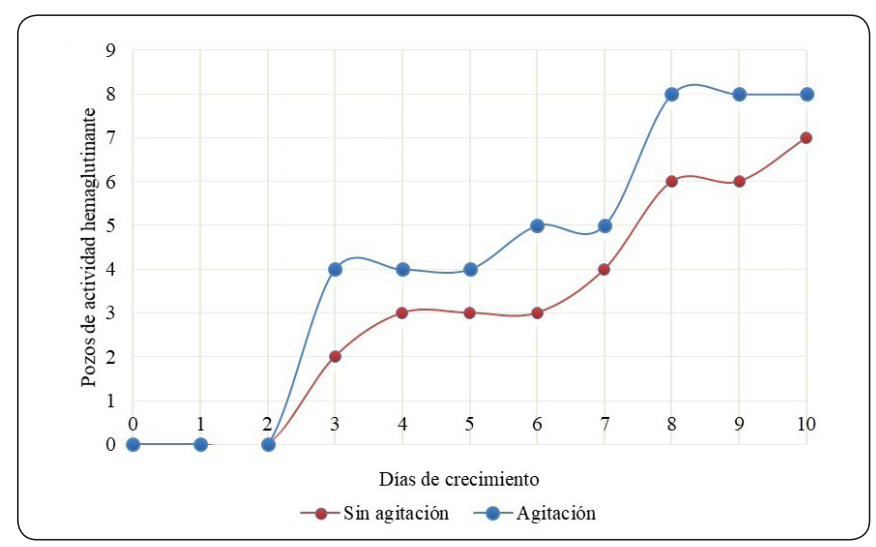

Gráfica 4. Cinética de actividad de la lectina con respecto a los días de crecimiento en caldo extracto de malta.

\section{Variación del pH}

En los medios de cultivo líquido hubo una variación significativa del $\mathrm{pH}$ : caldo suero de naranja (de 5.6 a 4), caldo papa dextrosa (de 5.8 a 3.96) y caldo extracto de malta (de 4.51 a 3.87) con respecto a los días de cultivo, pero no importante con respecto a los medios de cultivo. Con los datos obtenidos se eligió el medio caldo extracto de malta, por ser el más favorable a la adaptación del hongo y producción de lectina.

\section{Cuantificación de proteína}

En la Tabla III, se muestra $0.28 \mathrm{mg} / \mathrm{mL}$ de proteína en un medio con agitación y $0.25 \mathrm{mg} / \mathrm{mL}$ sin agitación en el día 10 donde se alcanzó un mayor número de pozos activos en ese periodo. La cantidad total en mg de proteína de $L$. volemus obtenidos en todo el medio de cultivo fueron de $13.95 \mathrm{mg} /$ total con agitación y $12.67 \mathrm{mg} /$ total sin agitación, resultados mayores a los obtenidos con el cuerpo fructífero.

\section{Inhibición con carbohidratos}

Los carbohidratos utilizados para la inhibición de la actividad de la lectina fueron: D-glucosamina, Quitina, D (-) Fructosa, 


\section{Control negativo (-)}

Caldo extracto de malta en condiciones de agitación

Caldo extracto de malta en condiciones estáticas

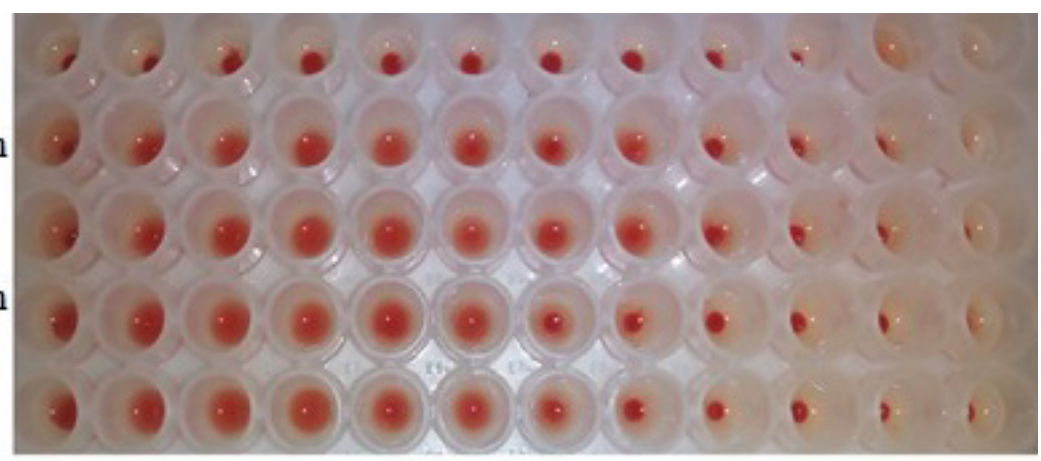

Figura 3. Actividad hemaglutinante de $L$. volemus a los 9 días de crecimiento (Fila 1 control negativo (-), Fila 2 y 3 Caldo extracto de malta en condiciones de agitación, Fila 4 y 5 Caldo extracto de malta en condiciones estáticas).

Tabla III. Concentración de proteína $(\mathrm{mg} / \mathrm{mL})$ de $L$. volemus en medio de cultivo líquido.

\begin{tabular}{|c|c|c|}
\hline & Caldo Extracto de malta & \\
\hline Día & Sin agitación & Agitación 50 rpm \\
\hline 1 & 0.10 & 0.11 \\
\hline 2 & 0.10 & 0.12 \\
\hline 3 & 0.14 & 0.13 \\
\hline 4 & 0.16 & 0.15 \\
\hline 5 & 0.19 & 0.16 \\
\hline 6 & 0.20 & 0.18 \\
\hline 7 & 0.20 & 0.19 \\
\hline 8 & 0.22 & 0.22 \\
\hline 9 & 0.22 & 0.23 \\
\hline 10 & 0.25 & 0.28 \\
\hline
\end{tabular}

Manosa, Sacarosa, Lactosa, Xilosa, N-acetil-galactosamina; sin embargo, ninguno de éstos la inhibió a una concentración de $0.4 \mathrm{M}$. Esto podría deberse a que la lectina de L. volemus reconoce un carbohidrato o glicoproteína más complejo, como es el caso de Lactarius deterrimus, donde se obtuvo una lectina homodimérica de $37 \mathrm{kDa}$ con especificidad al azúcar ${ }^{\beta}$-Dgalactosil $(1 \rightarrow 3)-\mathrm{D}$ - N-acetil-galactosamina(Guillot, Damez, Dusser, Didier \& Didier, 1993) y de Lactarius deliciosus con la lectina dimérica, $37 \mathrm{kDa}$ (Subunidades de 19 y $18 \mathrm{kDa}$ ) con afinidad al azúcar D-Gal $13 \rightarrow 3 \mathrm{D}-$ GalNAc (Guillot, Giollant, Damez \& Dusser, 1991).

\section{Discusión}

Se han publicado trabajos sobre lectinas en medios de cultivo líquidos y cepas de hongos basidiomicetos como $L$. volemus. Para este estudio al ser cultivado $L$. volemus in vitro se detectó la presencia de lectina, demostrando su potencialidad como una fuente de lectinas fúngicas. El mayor crecimiento miceliar de L. volemus en condiciones de agitación fue en el medio caldo extracto de malta, seguido del caldo suero de naranja.
La actividad de la lectina del hongo está relacionada con la concentración de la biomasa durante su etapa de desarrollo, tiempo de fermentación y la inoculación de los extractos líquidos con los discos agar-micelio y no a una resiembra. La inoculación de un medio líquido con fragmentos del hongo, acelera el proceso de fermentación, por lo que este método puede considerarse como una preinoculación en una cantidad mínima del medio líquido, para su posterior inoculación en matraces a mayor volumen.

Los pozos que presentaron actividad de la lectina fue cuando el hongo se encontraba en su fase exponencial, ya que en la fase de adaptación al medio no se presentó actividad en ningún pozo. En cuanto a la influencia del $\mathrm{pH}$, los bioensayos indican que la actividad de la lectina está en un rango de pH entre 4.6 y 3.7 , observando que ésta se presenta cuando el medio tiende a acidificarse, ya que el micelio del hongo participa en la producción de ácidos orgánicos y la absorción de iones, lo que provoca la acidificación del medio de cultivo; la biomasa miceliar del hongo también produce disminución del pH en el medio. La concentración inicial de la biomasa en cada bioensayo realizado demuestra que la actividad de la lectina está relacionada con esa concentración durante su etapa de desarrollo, así como la inoculación del extracto de malta con agar de seis días de crecimiento del hongo, que es cuando comienza un aumento considerable de lectina.

Consideramos que fue acertada la elección de una temperatura de incubación del hongo de $25 \pm 2{ }^{\circ} \mathrm{C}$ a $50 \mathrm{rpm}$ y 6 discos de agar-micelio para el bioensayo establecido para 10 días de crecimiento, ya que se obtuvo el mayor número de pozos con actividad hemaglutinante, en comparación con los de los bioensayos que citan solo 3 pozos activos (con 3 discos de agar-micelio y $100 \mathrm{~mL}$ del medio) (Matías, 2016).

\section{CONCLUSIONES}

Lactarius volemus, además de las características propias de su especie, puede ser cultivado a partir de fragmentos de sí mismo. 
La mayor producción de biomasa miceliar y actividad de la lectina de L. volemus en un medio de cultivo caldo extracto de malta se logró en condiciones de agitación y con inoculación de 6 discos de agar-micelio.

Los resultados obtenidos de la producción de biomasa miceliar del hongo L. volemus, con alto valor nutritivo como se mencionó inicialmente, sirven de base para estudios posteriores en la búsqueda de lectinas y otras sustancias en cultivo in vitro.

\section{Agradecimientos}

Al Tecnológico Nacional de México/Instituto Tecnológico de Oaxaca por el apoyo financiero para la realización del proyecto, Clave: 5245.19-P y al Consejo Nacional de Ciencia y Tecnología (CONACYT) por la Beca $\mathrm{N}^{\circ} 484409$, con $\mathrm{N}^{\circ}$ de Registro 632262.

\section{REFERENCIAS}

Boa, E. (2004). Los hongos silvestres comestibles. Perspectiva global de su uso e importancia para la población, No. 17. FAO, Roma. p. 161

Bradford, M. M. (1976). A rapid and sensitive method for the quantitation of microgram quantities of protein utilizing the principle of protein-dye binding. Analytical Biochemistry, 72(1-2), 248-254. https://doi.org/10.1016/00032697(76)90527-3

Errotari. Asociación Micológica de Durango [En línea]. [Consultado el: 18/02/2017]. Disponible en http://www. errotari.com/Micologia/especie.php?1754

García-Mendoza, A. J., J. Ordóñez, M. \& Briones-Salas, M. (2004). Biodiversidad de Oaxaca. Instituto de BiologíaUniversidad Nacional Autónoma de México, Fondo Oaxaqueño para la Conservación de la Naturaleza y World Wild Life Fund. México, D. F., México. 602 p.

Giollant, M., Guillot, J., Damez, M., Dusser, M., Didier, P. \& Didier, E. (1993). Characterization of a Lectin from Lactarius deterrimus (Research on the Possible Involvement of the Fungal Lectin in Recognition between Mushroom and Spruce during the Early Stages of Mycorrhizae Formation).
PlantPhysiology, 101(2), 513-522.https://doi.org/10.1104/ pp.101.2.513

Guillot, J., Giollant, M., Damez, M. \& Dusser, M. (1991). Isolation and Characterization of a Lectin from the Mushroom, Lactarius deliciosus. The Journal of Biochemistry, 109(6), 840-845. https://doi.org/10.1093/ oxfordjournals.jbchem.a123468

Khan, F. \& Khan, M. I. (2011). Fungal Lectins: Current Molecular and Biochemical Perspectives. International Journal of Biological Chemistry, 5(1), 1-20. https://doi. org/10.3923/ijbc.2011.1.20

Kobert, R. (1893). Lehrbuch der Intoxikationen. Fredinand Enke; Stuttgart, Germany: 1893.

Matías, L. G. (2016). Producción de lectinas en un microbioreactor. Proyecto actualmente en desarrollo

Panchak1, L. V. \& Antonyuk, V. O. (1999) Purification of lectin from fruiting bodies of Lactarius rufus (Scop.: Fr.) Fr. and its carbohydrat especificity. 2007 Mar-Apr; 79(2):123-8. PMID: 18030759

Sandoval, J. A. (2016). Aislamiento y caracterización de lectina de Lactarius volemus. Proyecto actualmente en desarrollo.

Tsivileva, O. M., Nikitina, V. E. \& Loshchinina, E. A. (2008). Isolation and characterization of Lentinus edodes (Berk.) singer extracellular lectins. Biochemistry (Moscow). p 73:1154-1161

Yingying, W., Hexiang, W. \& TziBun, N. (2011) Purification and characterization of a lectin with antiproliferative activity to ward cancer cells from the dried fruit bodies of Lactarius flavidulus. ELSERVIER, Volume 346, Issue 16, 29 November 2011, Pages 2576-2581. DOI: 10.1016/j. carres.2011.09.005

Zamora-Martínez, M. C., González Hernández, A., Islas Gutiérrez, F., Cortés Barrera, E. N., \& López Valdez, L. I. (2014). Distribución geográfica y ecológica de 13 especies de hongos silvestres comestibles en Oaxaca. Revista mexicana de ciencias forestales, 5(21),76-93. ISSN: 20071132. Disponible en: https://www.redalyc.org/articulo. oa? $\mathrm{id}=634 / 63439003010$ 